\title{
Design and Implementation of Multi-Agent System for Load Shedding in Microgrid
}

\author{
Yujin $\operatorname{Lim}^{+} \cdot$ Hak-Man Kim ${ }^{++}$
}

\begin{abstract}
In an islanded operation mode of a microgrid, load shedding is used to balance between the power supplied and the power demanded. The conventional load-shedding schemes have considered that a load uses a continuous range of values to present its load demand. However, in reality, some loads use integer and discrete values. We design a multi-agent system for the load shedding with consideration of the discrete characteristic of load demands. Besides, we define a control architecture, functionalities of agents, and interactions among agents for implementation of the system. Through experiments in various test scenarios, we show the feasibility and performance of the system.
\end{abstract}

Keywords : Microgrid, Load Shedding, Multi-Agent System

\section{마이크로그리드 환경에서 부하차단을 위한 다중 에이전트 시스템의 설계 및 구현}

임 유 진 ${ }^{\dagger}$ 김 학 만 ${ }^{++}$

\section{요 약}

\begin{abstract}
마이크로그리드(microgrid)의 독립적 운용방식(islanded operation mode)에서는 전력 공급량과 전력 수요량 사이의 균형을 맞추기 위하여 부 하차단(load shedding) 기법이 사용된다. 기존의 부하차단 기법들은 부하의 요구량이 연속적인 값의 범위를 갖는다고 가정하였다. 그러나 일부 부하는 이산적인 정수 값을 사용하여 자신의 요구량을 나타낸다. 따라서 본 논문에서는 독립형 운용방식 환경에서 부하 요구량의 이산적인 특 성을 고려한 부하차단 기법을 다중 에이전트 시스템을 이용하여 설계한다. 또한 시스템 구조, 에이전트 기능, 그리고 에이전트 간 통신 프로토 콜을 추가로 정의 및 확장함으로써 시스템을 구현하였으며, 구현된 시스템을 기반으로 다양한 시나리오 환경에서의 실험을 통하여 그 성능을 증명하였다.
\end{abstract}

키워드 : 마이크로그리드, 부하차단, 다중 에이전트 시스템

\section{1. 서 론}

마이크로그리드(Microgrid)는 전력 생산자로서의 분산 발 전기(DGs: Distributed Generations), 분산 저장기(DSs: Distributed Storages), 그리고 전력 소비자로서의 부하 (Loads)로 구성된 작은 규모의 전력 시스템으로 복수의 전 원 및 열원이 IT 기술을 이용하여 제어, 운용 및 관리되고

※ This work was supported under the framework of international cooperation program managed by the National Research Foundation of Korea(2012K2A2A4021447).

† 종신회원 : 수원대학교 정보미디어학과 조교수

†† 정 회 원 : 인천대학교 전기공학과 교수

논문접수: 2012 년 11 월 1 일

심사완료 : 2012년 11월 15일

* Corresponding Author:Hak-Man Kim(hmkim@incheon.ac.kr)
전력회사의 상용계통과 연계운전은 물론 독립운전이 가능한 온 사이트형 전력공급 시스템으로 정의된다[1-3]. 또한, 신 재생 에너지 전원, 마이크로 가스터빈, 연료전지 및 열병합 발전 등 다양한 형태의 전원이 연계 가능하고, 전력공급 신 뢰도 및 전력품질 향상, $\mathrm{CO}_{2}$ 저감, 손실절감 등의 장점으로 인하여 기존 대규모 전력계통(power grid)의 단점을 보완, 극복할 수 있는 잠재력을 가지고 있다. 이러한 마이크로그 리드 기술에 대하여 전 세계적으로 요소기기, 시스템 운영 기술, 에너지 관리 기술 등 마이크로그리드 시스템 제반 기 술에 대한 활발한 연구가 진행되고 있으며 특히, 유럽연합, 미국, 일본 등에서 마이크로그리드 시스템을 상용화하기 위 한 다양한 실증 프로젝트들이 진행되고 있다[4].

마이크로그리드의 운용 목표는 전력 공급량과 전력 수요 
량 사이의 균형을 맞추는 것이다. 이 균형이 깨지면 전력의 주파수가 변동하며, 이것이 기준 값 $(50 \mathrm{~Hz}$ 또는 $60 \mathrm{~Hz})$ 에서 크게 벗어나게 되면 전력 시스템은 안정적으로 운용될 수 없다. 이러한 균형 유지를 위해서는 마이크로그리드 구성 요소들 간 지능형 협력제어 운용기법이 요구된다. 지능형 협력제어 기법은 구성요소 간 자유로운 정보전달이 가능해 야하고, 사용자의 지시없이 스스로 또는 다른 구성 요소와 의 협상 후 판단하여 행동할 수 있어야 한다. 또한 어떤 입 력에 대해 자체적인 처리과정을 통해 자신에게 유리한 방향 으로 행동할 수 있어야 한다. 다중 에이전트 시스템 (Multi-Agent System: MAS)은 이러한 지능형 협력제어 기 법을 기반으로 마이크로그리드의 운용 목표를 달성하기 위 한 효율적인 기술이다[5-7]. 에이전트는 전체 시스템이 협력 기반 문제 해결이라는 공동의 목표를 향해 나아가도록, 자 율성과 자체 조직화 그리고 분산화의 특징을 가지는 소프트 웨어 또는 하드웨어 요소를 말한다[8].

본 논문에서는 전력 공급량과 전력 수요량 사이의 균형을 맞추기 위한 기법들 중 하나인 부하차단(load shedding) 기 법에 초점을 맞춘다. 부하차단이란 전력수급 균형(power balance) 유지를 위하여 의도적으로 전기 공급을 차단함으 로써 전력 시스템의 안정성을 확보하는 방법이다. 본 논문 에서는 이러한 부하차단을 위하여 다중 에이전트 시스템 기 반의 마이크로그리드 제어 시스템을 설계 및 구현한다. 이 를 위하여 먼저 부하차단을 위한 제어 구조를 정의하고, 설 계된 구조에서 각 구성 요소들의 기능을 정의한 다음, 실제 로 시스템을 구현한다. 또한 다양한 시나리오에서 실험을 통하여 시스템의 성능을 증명한다.

논문의 구성은 다음과 같다. 2절에서는 부하차단 기법을 소개한다. 3절에서는 다중 에이전트 시스템 기반의 부하차 단 시스템을 설계한다. 4절에서는 다양한 시나리오 환경에 서의 실험을 통하여 시스템의 동작성 및 성능을 증명한다. 마지막으로 5절에서 결론을 맺는다.

\section{2. 부하 차단}

마이크로그리드의 운용방식은 계통연결형 운용방식(gridconnected mode)과 독립형 운용방식(islanded mode)으로 나 뉜다. 계통연결형 운용방식은 상위 전력계통과 연계하여 에 너지 요금과 전력계통 혼잡에 따른 상위 전력계통의 수요관 리에 대응하고, 피크부하절감(peak load shaving) 및 실시간 전기요금에 대응하여 에너지 비용을 절감할 수 있다. 또한 신재생에너지의 불규칙한 출력 평준화와 무효전력 공급을 통한 마이크로그리드의 전압 품질을 향상시킬 수 있다[9]. 계통연결형 운용방식에서 마이크로그리드는 분산 발전기에 서 발생한 전력과 부하에서 요구한 전력 사이의 차이를 전 력계통과의 전력거래로 균형을 맞출 수 있다. 상위 전력계 통에서의 사고 등으로 인한 과도상태가 발생하였을 때, 마 이크로그리드는 전력품질을 유지하기 위하여 상위 전력계통 과 물리적으로 분리하여 운전하는 독립형 운용방식으로 동
작할 수 있다. 다시 말해서, 독립형 운용방식은 관리 목적이 나 경제적인 이유로, 또는 전력계통 구성 요소의 물리적인 장애로 인하여 전력계통에서 격리되어 운용하는 것이다. 만 약 전력 수요량이 전력 공급량보다 크다면 일부 부하와의 연결을 끊거나 전력 소비를 줄일 필요가 있다. 다시 말해서, 독립형 운용방식에서는 전력 공급과 전력 수요 사이의 균형 을 위하여 부하차단과 같은 기술이 사용된다. 마이크로그리 드는 시스템의 전압 안정성을 유지하고 시스템의 한계를 넘 는 과전압을 막기 위하여 부하차단 기법을 통하여 수락하거 나 거절할 부하의 양을 결정한다.

기존의 부하차단 기법에서는 부하 요구량이 연속적인 값의 범위를 갖는다고 가정하였다. 그러나 실제로 일부 부하의 요 구량은 이산적인 정수 값의 범위를 갖는다. 예를 들어, 부하 1 의 부하 요구량이 $30 \mathrm{kWh}$ 이고, 해당 부하 요구량은 TV 전 원을 위한 10 , 세탁기 전원을 위한 13 , 그리고 전등을 위한 7 , 이렇게 3 개의 하위 부하 요구량들로 구성된다고 가정해보자. 이때 기존의 부하차단 기법에서는 부하 1 의 부하 차단양을 8 로 결정할 수 있다. 이때, 부하 1 은 자신에게 허락된 $22 \mathrm{kWh}$ 의 전원으로 $\mathrm{TV}$ 는 켤 수 있지만, 세탁기까지 사용할 수는 없 게 된다. 따라서 부하 1 에게 할당된 $22 \mathrm{kWh}$ 의 전원 중에서 실제로 사용되는 전원은 $10 \mathrm{kWh}$ 뿐이고 나머지 $12 \mathrm{kWh}$ 는 사용 할 수 없게 된다. 따라서 이와 같은 부하 요구의 이산적인 특 성을 반영한 부하차단 기법이 요구된다. 본 논문에서는 마이 크로그리드의 독립형 운용 환경에서 부하 요구량의 이산적인 특성을 고려한 부하차단 시스템을 설계한다.

본 논문에서는 부하차단의 목적을 부하관리(load management)와 공정성(fairness)의 극대화로 설정하였다. 부 하관리란 부하에서의 전력 사용률, 즉 부하에게 할당된 전 력 대비 부하가 실제로 사용한 전력의 비율을 향상시키는 것을 의미한다. 예를 들어, 위의 예에서 부하 1 의 전력 사용 률은 $10 / 22=0.45$ 이다. 공정성이란 모든 부하가 전력을 공평 하게 할당받는 것을 의미한다. 본 논문에서는 이러한 목적 을 달성하기 위하여 게임이론을 적용하였다. 협동적 게임이 론의 협상 해법 중 대표적인 기법인 NBS(Nash Bargaining Solution) [10]를 사용하여 최적의 부하 차단양을 결정할 수 있다. 전력 공급량은 한정되어 있으므로, 부하의 전력요구량 이 공급량을 초과한다면 모든 부하 요구를 수용할 수 없게 된다. 이를 해결하기 위하여 $\mathrm{NBS}$ 를 기반으로 시스템 효율 (부하관리 및 공정성)을 극대화하기 위한 각 부하의 부하 차단양을 결정할 수 있다. 예를 들어, 전력 공급량이 $100 \mathrm{kWh}$ 이고, 3 개의 부하가 각기 $30 \mathrm{kWh}, 50 \mathrm{kWh}$, 그리고 $60 \mathrm{kWh}$ 의 전력 요구량을 가지는 경우를 가정해보자. 각 부 하의 부하 요구량을 구성하는 하위 부하 요구량은 다음과 같다: $30 \mathrm{kWh}=10+13+7,50 \mathrm{kWh}=20+11+6+13$, $60 \mathrm{kWh}=5+35+20$. 부하요구의 이산적인 특성을 고려한 $\mathrm{NBS}$ 를 기반으로 결정된 부하 차단양은 부하 1 은 7 , 부하 2 는 13 , 그리고 부하 3 은 20이 된다. 따라서 부하 요구량의 이산적인 특성으로 인하여 발생하는 문제 즉, 전력 사용률 감소 문제를 해결할 수 있다. 


\section{3. 다중 에이전트 시스템의 설계}

다중 에이전트 시스템은 환경을 인지하는 능력을 가진 에 이전트라는 자율 객체의 집합이며, 주로 제한된 환경 내에 서 동작한다. 에이전트는 시스템 내 자신의 역할에 따라 다 양한 수준의 지능을 가진다. 에이전트는 분석적으로 정의하 기 힘든 환경에서 성능 지표들을 최적화하는 것을 목표로 한다. 또한 에이전트는 다른 에이전트와 상호작용할 수 있 다. 이러한 상호작용은 단순한 정보교환일 수도 있고 또는 공동의 목표를 위하여 협상/협조하는 것일 수도 있다. 에이 전트들은 제안(propose), 역제안(counter-propose), 결정 수 락(accept), 또는 거절(reject)하는 과정을 거쳐 상호간 작용 할 수 있다.

본 논문에서는 마이크로그리드 환경에서 부하차단을 위한 다중 에이전트 시스템 설계를 위하여 마이크로그리드 구성 요소들을 다음과 같이 네 가지로 분류하였다 : 분산 발전기, 부하, 분산 저장기, 그리고 부하차단 통제센터(MGOCC-LS : MicroGrid Operation and Control Center for Load Shedding). MGOCC-LS는 기존의 마이크로그리드 운용센터 인 MGOCC [7]에 부하차단 기능을 추가한 것이다. 이러한 마이크로그리드 구성 요소들에는 각기 자신의 운영 목적에 적합한 에이전트들이 다음과 같이 할당된다 : $\mathrm{Ag}_{\mathrm{DG}}$, $\mathrm{Ag}_{\mathrm{LOAD}}, \mathrm{Ag}_{\mathrm{DS}}$, 그리고 $\mathrm{Ag}_{\mathrm{MGOCC}-\mathrm{LS}}$.

마이크로그리드는 interval 기반으로 운용된다. 또한 기존 의 전력 시스템과 마찬가지로 계획 단계와 실행 단계로 나 누어 구성된다. 예를 들어, 하루 24 시간을 시간단위로 24 개 의 interval로 나누어 운용 계획을 수립 및 실행할 수 있다. 다시 말해서, $i+1$ interval의 운용 계획은 $i$ interval에 수립 되며 $i+1$ interval에 실행된다. MGOCC-LS는 마이크로그리 드 운용을 위하여 시스템의 정보를 수집하고 시스템의 상황 을 관찰한다. 또한 수집한 정보를 바탕으로 다음 interval의 운용 계획을 세우고, 수립된 계획을 마이크로그리드 구성 요소들에게 통보한다. 마지막으로, 수립된 계획이 잘 실행되 는지 추적 관찰함으로써 마이크로그리드 운용을 제어한다.

본 논문에서는 마이크로그리드의 효율적인 운용 및 부하차 단을 위한 각 에이전트들의 기능을 다음과 같이 정의하였다.

- $\mathrm{Ag}_{\mathrm{DG}}$

- 다음 운용 interval을 위하여 연결된 DS의 공급 가능한 전력 양과 단가를 결정한다.

- $\mathrm{Ag}_{\mathrm{MGOCC}-\mathrm{LS}}$ 에게 공급 가능한 전력 양과 단가를 통보한다.

- $\mathrm{Ag}_{\mathrm{MGOCC}-\mathrm{LS}}$ 가 승인한 최종 전력 공급량을 통보 받는다.

- $\mathrm{Ag}_{\mathrm{MGOCC}-\mathrm{LS}}$ 가 승인한 전력량을 바탕으로 $\mathrm{DS}$ 에게 공급 시 작, 종료, 또는 설정 변경 등의 명령을 내린다.

- DS가 공급하는 전력량을 추적 관찰한다.

- $\mathrm{Ag}_{\mathrm{LOAD}}$

- 다음 운용 interval을 위하여 연결된 부하에서 요구하는 전력량을 예상 및 결정한다.
- $\mathrm{Ag}_{\mathrm{MGOCC}-\mathrm{LS}}$ 에게 필요한 부하량을 통보한다.

- $\mathrm{Ag}_{\mathrm{MGOCC}-\mathrm{LS}}$ 가 승인한 최종 부하량을 통보 받는다.

- 승인 받은 최종 부하량을 기반으로 부하에게 소비 시작, 종료, 또는 설정 변경 등의 명령을 내린다.

- 부하가 소비하는 전력량을 추적 관찰한다.

- $\operatorname{Ag}_{\mathrm{DS}}$

- 다음 운용 interval을 위하여 $\mathrm{Ag}_{\mathrm{MGOCC}-\mathrm{LS}}$ 부터 전력수급 균 형 정보를 통보 받는다.

- 연결된 DS의 $\mathrm{SoC}(\mathrm{State}$ of Charge)을 결정한다.

- $\mathrm{Ag}_{\mathrm{MGOCC}-\mathrm{LS}}$ 부터 통보받은 정보와 $\mathrm{SoC}$ 를 고려하여 전력 공급자(DS) 또는 전력 소비자(부하)로서의 자신의 역할을 결정한다.

- $\mathrm{Ag}_{\mathrm{MGOCC}-\mathrm{LS}}$ 에게 (전력 공급자로서) 공급 가능한 전력 양 과 단가를 통보하거나, (전력 소비자로서) 필요한 부하량 을 통보한다.

- $\mathrm{Ag}_{\mathrm{MGOCC}-\mathrm{LS}}$ 가 승인한 최종 전력 공급량 또는 부하량을 통 보 받는다.

- DS에게 충전, 방전, 또는 충/방전할 전력량 등에 대하여 명령한다.

- DS가 충/방전하는 전력량을 추적 관찰한다.

- $\mathrm{Ag}_{\mathrm{MGOCC}-\mathrm{LS}}$

- 다음 interval을 위한 마이크로그리드의 운용 계획 수립을 시작한다.

- 운용 계획 수립을 위하여 마이크로그리드를 구성하는 다 른 에이전트들로부터 관련 정보를 수집한다.

- 수집한 정보를 이용하여 전력수급 균형을 확인한다.

- 전체 전력 공급량이 전체 전력 수요량보다 적다면 부하 차단을 시작한다. (부하차단이 시작되면) 차단할 부하의 양을 결정한다.

- 전체 전력 공급량이 전체 전력 수요량보다 많다면, 전원을 공급할 $\mathrm{DS}$ 들과 해당 $\mathrm{DS}$ 들의 전력 공급량을 결정한다.

- $\mathrm{Ag}_{\mathrm{DS}}$ 를 위한 최종 전력 공급량과 $\mathrm{Ag}_{\mathrm{LOAD}}$ 를 위한 최종 부 하량을 결정한다.

- 에이전트들에게 최종 전력 공급량 또는 최종 부하량을 통 보한다.

- 통보된 마이크로그리드의 운용계획의 올바른 실행을 추적 관찰한다.

다중 에이전트 시스템의 중요한 기능 중 하나는 에이전트 간 정보교환이다. FIPA(Foundation for Intelligent Physical Agents)는 다중 에이전트 시스템을 위한 에이전트 간 통신 및 통신 프로토콜, 상호 운용성 등을 위한 표준을 정의하였 다[11]. FIPA-CNIP(Contract Net Interaction Protocol)은 에 이전트 간 통신을 위하여 $\mathrm{CFP}, \mathrm{PROPOSE}, \mathrm{REFUSE}$, ACCEPT, REJECT, FAILURE, 그리고 INFORM 등을 포함 한 performative 집합을 정의하였다. 이러한 FIPA-CNIP performative들은 마이크로그리드 환경에서 에이전트 간 통 
Table 1. Performatives for load shedding in the microgrid

\begin{tabular}{|c|c|}
\hline Performative & Purpose \\
\hline CFP & sent by $\mathrm{Ag}_{\mathrm{MGOCC}-\mathrm{LS}}$ to initiate the microgrid operational process \\
\hline $\begin{array}{l}\text { PROPOSE } \\
\text { SUPPLY }\end{array}$ & $\begin{array}{l}\text { sent by } A g_{D G} \text { to } A g_{M G O C C-L S} \text { in order to propose the amount of power supplied } \\
\text { with the cost per unit }\end{array}$ \\
\hline $\begin{array}{l}\text { PROPOSE } \\
\text { LOAD }\end{array}$ & sent by $\mathrm{Ag}_{\mathrm{LOAD}}$ to $\mathrm{Ag}_{\mathrm{MGOCC}-\mathrm{LS}}$ in order to propose the amount of load demanded \\
\hline REFUSE & sent by $\mathrm{Ag}_{\mathrm{DG}} / \mathrm{Ag}_{\mathrm{DS}} / \mathrm{Ag}_{\mathrm{LOAD}}$ to refuse to send a proposal \\
\hline ACCEPT & sent by $\mathrm{Ag}_{\mathrm{MGOCC}-\mathrm{LS}}$ to accept a proposal of $\mathrm{Ag} \mathrm{DG}_{\mathrm{DG}} / \mathrm{Ag}_{\mathrm{DS}} / \mathrm{Ag}_{\mathrm{LOAD}}$ \\
\hline REJECT & sent by $\mathrm{Ag}_{\mathrm{MGOCC}-\mathrm{LS}}$ to reject a proposal of $\mathrm{Ag}_{\mathrm{DG}} / \mathrm{Ag}_{\mathrm{DS}} / \mathrm{Ag}_{\mathrm{LOAD}}$ \\
\hline FAILURE & $\begin{array}{l}\text { sent by } \mathrm{Ag}_{\mathrm{DG}} / \mathrm{Ag}_{\mathrm{DS}} / \mathrm{Ag}_{\mathrm{LOAD}} \text { to } A g_{\mathrm{MGOCC}-\mathrm{LS}} \text { in order to tell a requested action to be } \\
\text { failed }\end{array}$ \\
\hline INFORM & $\begin{array}{l}\text { sent by } \mathrm{Ag}_{\mathrm{DG}} / \mathrm{Ag}_{\mathrm{DS}} / \mathrm{Ag}_{\mathrm{LOAD}} \text { to } \mathrm{Ag}_{\mathrm{MGOCC}-\mathrm{LS}} \text { in order to tell results of action to be } \\
\text { carried out }\end{array}$ \\
\hline
\end{tabular}

신을 위하여 확장되었다[7]. 다시 말해서, PROPOSE 메시지 를 PROPOSE SUPPLY와 PROPOSE LOAD의 두 개의 메 시지로 나누었다. 이는 $\mathrm{DG}$ 와 같은 전력 공급자를 위한 PROPOSE 메시지는 전력 공급량과 단가 정보를 포함하고 있으며, 부하와 같은 전력 소비자를 위한 PROPOSE 메시지 는 부하량 정보를 포함하고 있기 때문이다. Table 1은 마이 크로그리드 운용을 위한 FIPA-CNIP performative들을 자세 히 설명하고 있다.

Fig. 1은 Table 1에서 설명된 FIPA-CNIP performative들 의 교환 흐름을 보인 것이다. $\mathrm{Ag}_{\mathrm{MGOCC}-\mathrm{LS}}$ 는 $\mathrm{Ag}_{\mathrm{DG}}$ 와 $\mathrm{Ag}_{\mathrm{LOAD}}$ 들에게 다음 interval을 위한 운용 계획 수립의 시작을 알리 는 $\mathrm{CFP}$ 메시지를 전송한다. 이를 수신한 $\mathrm{Ag}_{\mathrm{DG}}$ 와 $\mathrm{Ag}_{\mathrm{LOAD}}$ 들 은 PROPOSE SUPPLY와 PROPOSE LOAD 메시지를 $\mathrm{Ag}_{\mathrm{MGOCC}-\mathrm{LS}}$ 에게 전송한다. $\mathrm{Ag}_{\mathrm{DG}}$ 와 $\mathrm{Ag}_{\mathrm{LOAD}}$ 들로부터 메시지 를 수신한 $\mathrm{Ag}_{\mathrm{MGOCC}-\mathrm{LS}}$ 는 수집된 정보를 기반으로 전력수급 균형을 확인한 후, 해당 정보를 $\mathrm{AgDS}$ 에게 전송한다. $\mathrm{Ag}_{\mathrm{DS}}$ 는 전력수급 균형 정보를 기반으로 전력 공급자 또는 전력 소비자로서의 자신의 역할을 결정한 후, $\mathrm{PROPOSE}$ SUPPLY 또는 PROPOSE LOAD 메시지를 전송한다. 이를 수신한 $\mathrm{Ag}_{\mathrm{MGOCC}-\mathrm{LS}}$ 는 다시 전력수급 균형을 확인한다. 이때 전력 공급량이 전력 수요량보다 작을 경우 부하차단이 시작

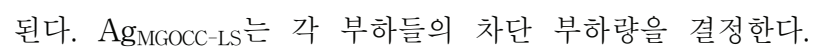
이를 기반으로 $\mathrm{Ag}_{\mathrm{DG}}, \mathrm{Ag}_{\mathrm{LOAD}}$, 그리고 $\mathrm{Ag}_{\mathrm{DG}}$ 들에게 최종 승 인된 최종 전력 공급량 또는 부하량을 통보하기 위하여 $\mathrm{ACCEPT}$ 메시지를 전송한다.

본 논문에서는 에이전트 간 교환되는 메시지 형식을 정의 하기 위하여 KQML(Knowledge Query and Manipulation Language)을 사용하였으며, 정의된 메시지 형식은 다음과 같다.

(<performative $>$ :from <에이전트 이름> :to <에이전트 이름> :content $<\mathrm{OAV}$ 형 데이터>)

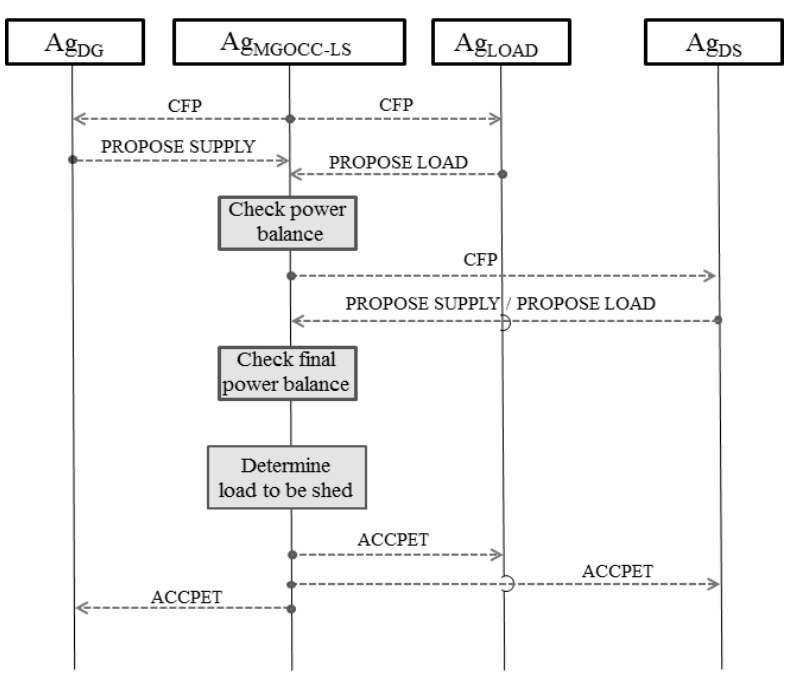

Fig. 1. Message flow among agents for load shedding in the microgrid

(Msg :performative propose-load :to ?to

:content (m_propose_load :from ?my_name :amount ?load_demand :subdemand ?sub_load_demands :interval ?interval))

Fig. 2. The PROPOSE LOAD message format

$<\mathrm{OAV}$ 형 데이터>는 객체, 객체의 속성, 그리고 속성 값 으로 구성된다. 본 논문에서는 부하요구의 이산적인 특성 을 부하차단에 반영하기 위하여 PROPOSE LOAD performative를 확장하였다. 부하가 자신의 부하 요구량을 제시하기 위하여 PROPOSE $\mathrm{LOAD}$ 를 $\mathrm{Ag}_{\mathrm{MGOCC}-\mathrm{LS}}$ 에게 전송 할 때 부하 요구량뿐만 아니라 그것을 구성하는 하위 부하 요구량 또한 통보한다. Fig. 2는 시스템에서 구현된 PROPOSE LOAD performative의 메시지 형식이다. 


\section{4. 시스템 구현 및 성능 평가}

본 논문에서는 앞서 제안한 시스템을 $\mathrm{ADIPS}$ (Agentbased architecture of Distributed Information Processing System)/DASH(Distributed Agent System based on Hybrid Architecture) 플랫폼을 사용하여 구현하였다[12].

시스템의 동작성과 효율성을 보이기 위하여, 하나의 $\mathrm{Ag}_{\mathrm{MGOCC}-\mathrm{LS}}$, 3개의 $\mathrm{Ag}_{\mathrm{DG}}$, 그리고 10 개의 $\mathrm{Ag}_{\mathrm{LOAD}}$ 로 구성된 실험환경을 설정하였다. 전체 전력 공급량은 $650 \mathrm{kWh}$ 로 $\mathrm{DG}$ $1=200 \mathrm{kWh}, \mathrm{DG} 2=200 \mathrm{kWh}$, 그리고 DG 3=250kWh로 구성된 다. 전체 부하 요구량은 $1300 \mathrm{kWh}$ 로 각 $\mathrm{Ag}_{\mathrm{LOAD}}$ 의 부하 요구 량은 $\{20,50,70,100,120,150,170,180,190,250\}$ 이다. 또 한 각 $\mathrm{AgLOAD}$ 의 부하 요구량은 하위 부하 요구량들의 집 합으로 구성된다. 예를 들어 $\mathrm{AgLOAD} 10$ 인 경우, 부하 요 구량은 $250 \mathrm{kWh}$ 이며, 이는 다음과 같은 하위 부하 요구량으 로 구성된다: $\{25,24,16,17,38,14,14,16,25,16,15,30\}$. 부하 별 하위 부하 요구량은 포아송(Poisson) 분포를 따른 다. 또한 각 부하에 따른 하위 부하 요구량 집합의 크기는 $\delta$ 보다 작게 설정한다.

Fig. 3은 다중 에이전트 시스템을 기반으로 6 대의 $\mathrm{PC}$ 에 구축한 마이크로그리드 분산 시스템을 보이고 있다. 각 $\mathrm{PC}$ 들은 인터넷으로 연결되어 통신한다. Fig. 4는 실험 시나리 오를 설정하기 위한 DASH/IDEA [12]기반 다중 에이전트 시스템 화면이다. Fig. 5 와 Fig. 6 는 $\mathrm{Ag}_{\mathrm{MGOCC}-\mathrm{LS}}$ 의 운용 화 면이다. 각 화면의 상단은 마이크로그리드 운용 중에 수집

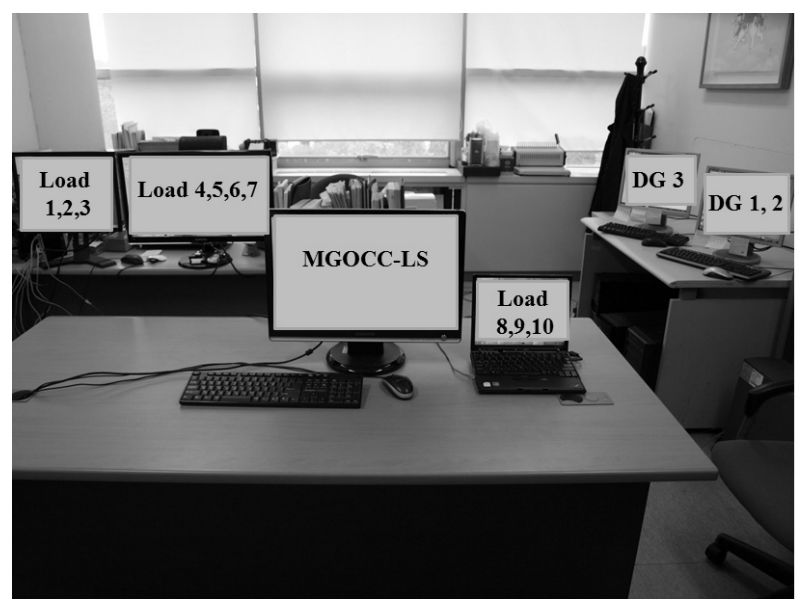

Fig. 3. Implemented system in a distributed environment

되거나 결정된 내용이 표시되고, 화면의 하단은 에이전트 간 교환된 메시지가 표시된다. Fig. 5는 $\mathrm{Ag}_{\mathrm{MGOCC}-\mathrm{LS}}$ 가 $\mathrm{Ag}_{\mathrm{DG}}$ 와 $\mathrm{Ag}_{\mathrm{LOAD}}$ 들과 $\mathrm{CFP}, \mathrm{PROPOSE} \mathrm{SUPPLY}$, 그리고 $\mathrm{PROPOSE} \mathrm{LOAD}$ 메시지를 주고받음으로써, 전체 전력 공 급량과 전체 부하 요구량 정보를 수집하는 화면이다. Fig. 6 는 Fig. 5에서 수집된 정보를 기반으로 부하 요구량의 이산 적인 특성을 반영한 $\mathrm{NBS}$ 를 이용하여 각 $\mathrm{Ag}_{\mathrm{LOAD}}$ 별 부하 차 단양을 $\{0,0,22,31,33,80,110,81,108,185\}$ 와 같이 결정 하고, 이를 $\mathrm{ACCEPT}$ 메시지를 통해 각 에이전트에게 통보 하는 화면이다.

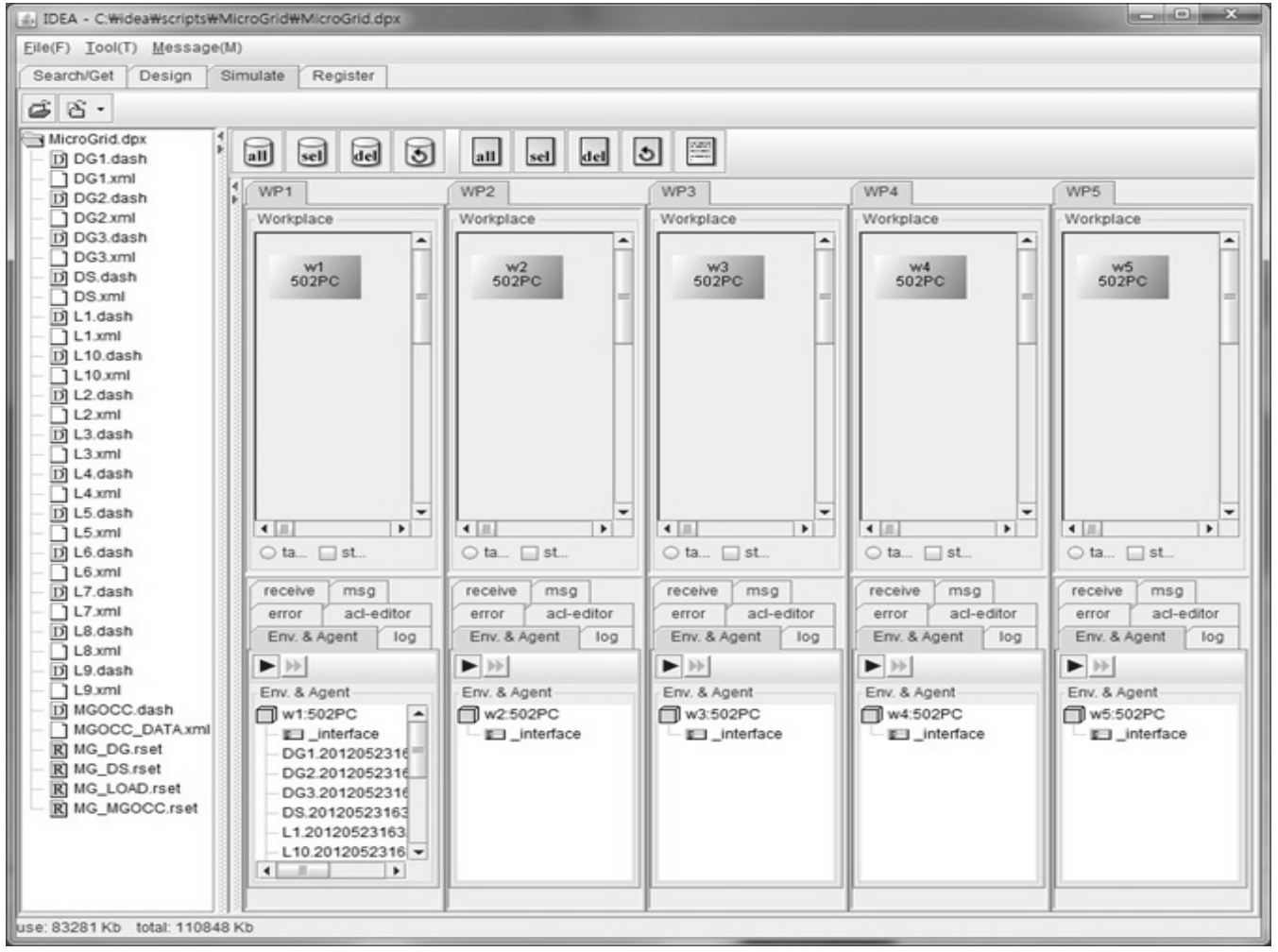

Fig. 4. Window for the configuration of test scenario 


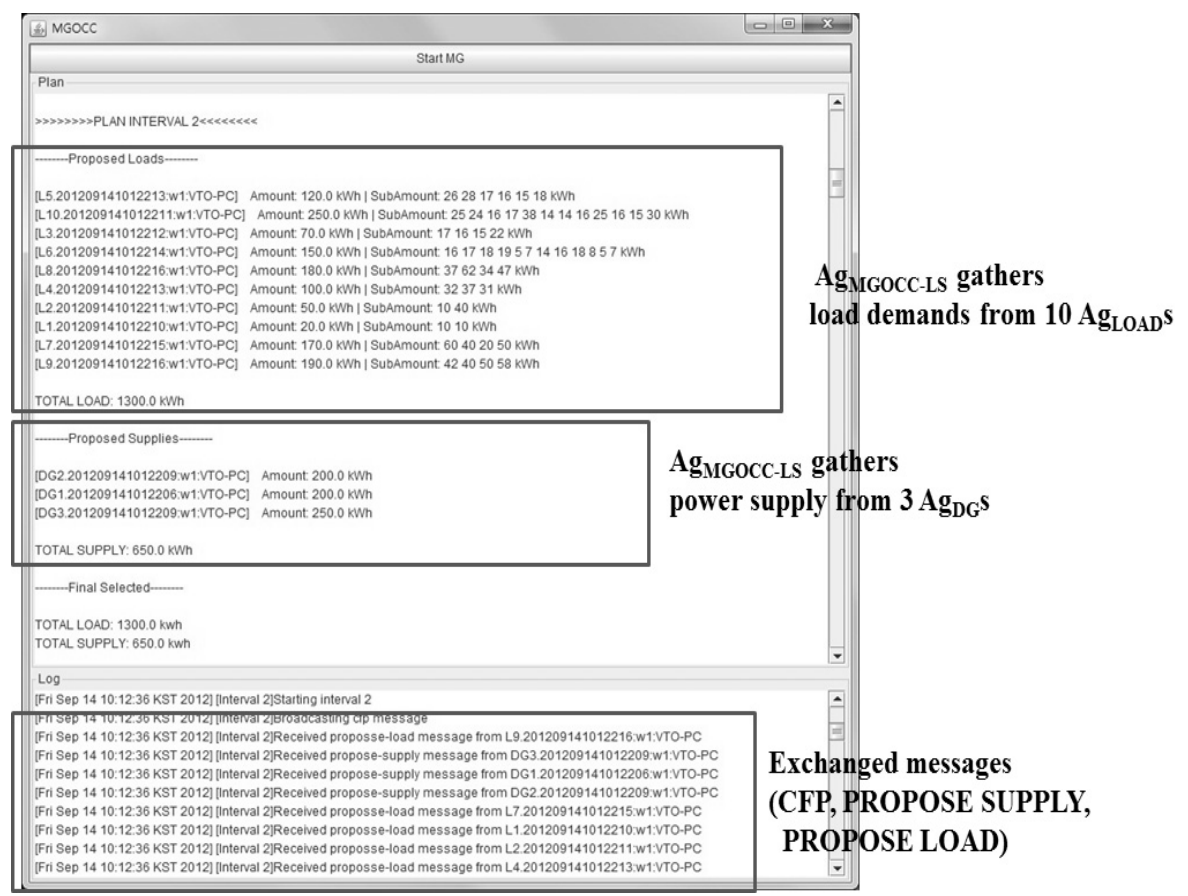

Fig. 5. Window for information gathering of Agmaocc-Ls

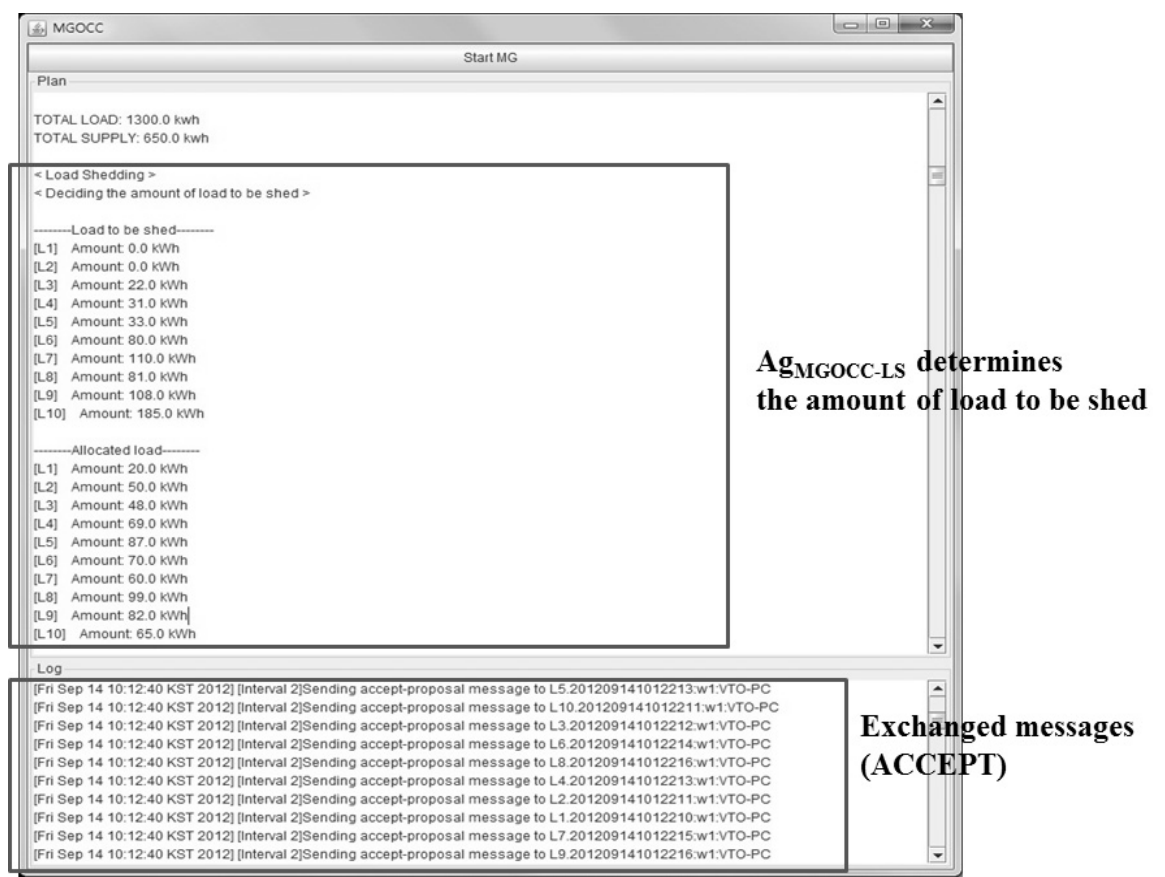

Fig. 6. Window for decision making of Agmcocc-LS

Fig. 7은 $\mathrm{Ag}_{\mathrm{LOAD}}$ 2가 $\mathrm{Ag}_{\mathrm{MGOCC}-\mathrm{LS}}$ 로부터 $\mathrm{CFP}$ 메시지를 수 신하고, PROPOSE LOAD 메시지를 송신하는 화면이다. 또한

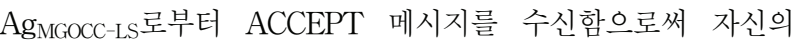
부하 요구량인 $50 \mathrm{kWh}$ 를 모두 할당받았음(부하 차단양이 없 음)을 알 수 있다. 본 논문에서는 마이크로그리드 운용을 위하 여 하루를 24개의 interval로 나누어 한 시간마다 각 interval 에 대응되도록 하였다. 또한 매 interval마다 각 $\mathrm{Ag}_{\mathrm{LOAD}}$ 의 부
하 요구량과 각 부하 요구에 따른 하위 부하 요구 집합을 변 화시켰다. Fig. 8은 하루 동안의 전체 부하 요구량, 전체 전력 할당량(= 전체 전력 요구량 - 전체 부하 차단양), 그리고 잔 여 전력량(= 전체 전력 공급량 - 전력 할당량)을 보이고 있 다. 그림은 개발된 시스템의 운용성을 증명하고 있으며 또한 부하 요구의 이산적인 특성을 고려한 $\mathrm{NBS}$ 를 이용한 부하차단 기법이 효율적으로 부하차단을 수행하고 있음을 보이고 있다. 


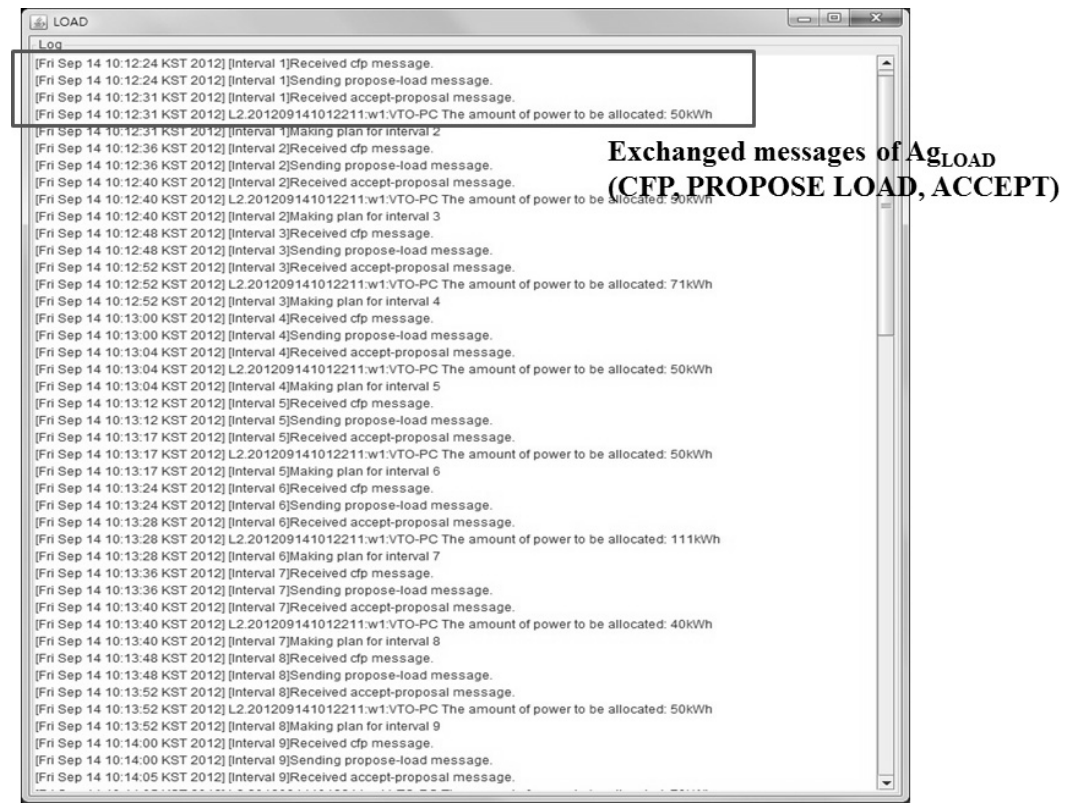

Fig. 7. Window for the operation of AgLOAD 2

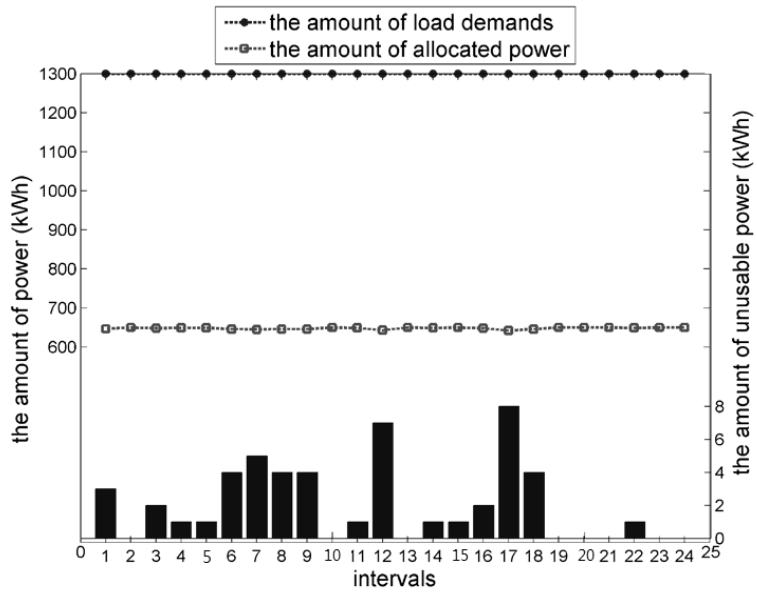

Fig. 8. System operation for one day

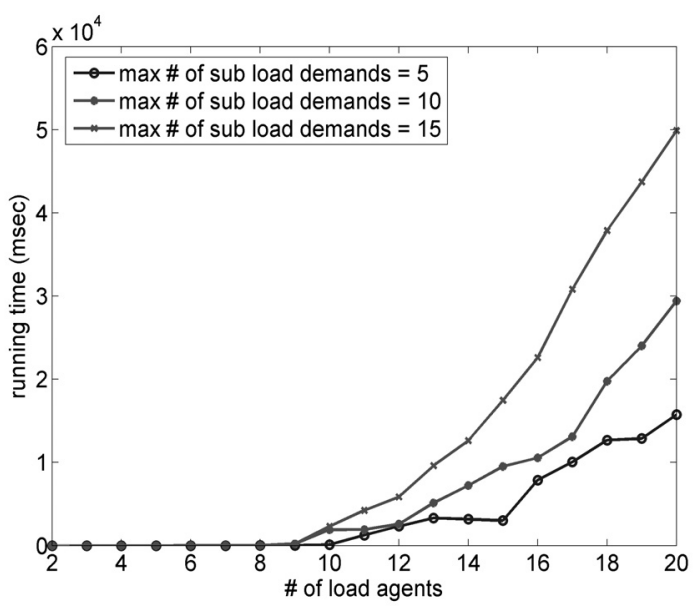

Fig. 9. The running time of our load-shedding system
Fig. 9는 $\mathrm{Ag}_{\mathrm{LOAD}}$ 의 수를 2 부터 20까지 변화시키면서 $\mathrm{NBS}$ 기법의 실행시간을 측정한 결과이다. 전체 부하 요구 량은 $1300 \mathrm{kWh}$ 로 부하의 수가 변해도 전체 부하 요구량은 일정하다. 또한 각 부하의 하위 부하 요구 집합의 크기, $\delta$ 를 변화시켜가면서 측정하였다. NBS 기법은 NP-hard 문제 [13]이기 때문에 부하차단을 위한 실행 시간의 대부분이 $\mathrm{NBS}$ 해를 구하는데 소요되기 때문에 본 실험은 중요한 의 미를 가진다. 그림에서 보는 바와 같이 최대 1 분 이내에 해 를 얻을 수 있음을 확인할 수 있다. 또한 부하의 개수가 늘 어난다 하더라도, NBS 해를 polynomial time에 구할 수 있 는 다양한 근사 알고리즘(approximation algorithm) [14]이 제안되어 있으므로 $\mathrm{NBS}$ 로 인한 성능 저하 문제는 발생하지 않을 것으로 예상된다.

\section{5. 결 론}

본 논문에서는 독립형 운용방식으로 동작하는 마이크로그 리드 환경에서 부하 차단을 위한 에이전트 기반 협력제어 시스템을 개발하였다. 기존의 부하차단 기법들은 부하 요구 량의 이산적인 특징을 고려하지 않아 성능 상의 많은 제약 을 가지고 있었다. 따라서 본 논문에서는 부하요구의 이산 적인 특징을 고려한 마이크로그리드 부하차단 시스템을 개 발하였다. 개발된 시스템은 부하차단을 위하여, 마이크로그 리드를 구성하는 각 에이전트의 기능을 정의하고, 에이전트 간 통신 프로토콜을 확장하였으며, 또한 $\mathrm{NBS}$ 에 기반 한 부 하차단 기법을 제안하였다.

시스템의 동작성과 성능을 증명하기 위하여 실제 분산 환 경에 마이크로그리드 에이전트 시스템을 구현하고, 다양한 시나리오에서 실험을 진행하였다. 


\section{참 고 문 헌}

[1] N. Hatziargyriou, H. Asano, R. Iravani, and C. Marnay, "Microgrids," IEEE Power Energy, Vol.5, No.4, pp.78-94, 2007

[2] N. D. Hatziargyriou, "Microgrids," IEEE Power Energy, Vol.6, No.3, pp.26-29, 2008.

[3] S. Suryanarayanan, J. Mitra, and S. Biswas, "A Conceptual Framework of a Hierarchically Networked Agent-based Microgrid Architecture," Proceedings of the IEEE Transmission and Distribution Conference and Exposition, New Orleans, LA, USA, April 19-22, 2010.

[4] M. Barnes, J. Kondoh, H. Asano, J. Oyarzabal, G. Ventakaramanan, R. Lasseter, N. Hatziargyriou, and T. Green, "Real-Word MicroGrids - An Overview," Proceedings of IEEE International Conference of System of Systems Engineering, Hong-Kong, China, pp.1-8, April, 2007.

[5] A. Dimeas and N. D. Hatziagyriou, "Agent based Control for Microgrids," Proceedings of IEEE Power Engineering Society General Meeting, Tampa, FL, USA, pp.1-5, June 24-28, 2007.

[6] A. L. Dimeas and N. D. Hatziargyriou, "Operation of a Multiagent System for Microgrid Control," IEEE Transactions on Power Systems, Vol.20, No.3, pp.1447-1455, 2005.

[7] H.-M. Kim and T. Kinoshita, "A Multiagens System for Microgrid Operation in the Grid-interconnected Mode," KIEE Journal of Electrical Engineering \& Technology, Vol.5, No.2, pp.246-254, 2011.

[8] M. J. Woolridge, "An Introduction to Multi-agent Systems," John Wiley \& Sons, New York, NY, 2002.

[9] J-H. Jeon, K-H. Kim, C-S. Hwang, J-M Kim, "A Novel Frequency Tracker for Islanded-Mode Operation in Microgrid," The Transactions of the Korea Institute of Electrical Engineers, KIEE, Vol.60, No.7, pp.1331-1338, 2011.
[10] Y. Lim, H.-M. Kim, J. Park, and T. Kinoshita, "A Game Theoretic Approach for Load Shedding in the Islanded Microgrid," Information Journal, In Press.

[11] FIPA. Available online: http://www.fipa.org.

[12] IDEA/DASH Tutorial. Available online: http://www.ka.riec. tohoku.ac.jp/idea/index.html (accessed on Oct. 2012).

[13] C. H. Papadimitriou and M. Yannakakis, "On the Approximability of Trade-Offs and Optimal Access of Web Sources," In Proceedings of the IEEE Symposium Foundations of Computer Science, pp.86-92, July, 2000.

[14] S. Boyd and L. Vandenberghe, "Convex Optimization," Cambridge University Press, United Kingdom, 2004.

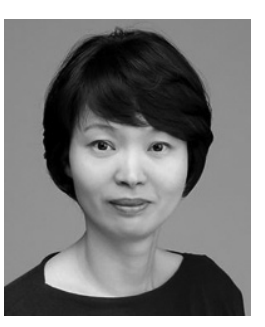

\section{임 유 진}

e-mail : yujin@suwon.ac.kr

1995년 숙명여자대학교 전산학과(학사)

1997년 숙명여자대학교 전산학(석사)

2000년 숙명여자대학교 전산학(박사)

2000년 서울대학교 박사후연구원

2000년 2002년 UCLA 박사후연구원

2003년 2004년 삼성종합기술원 전문연구원

2004년 현 재 수원대학교 정보미디어학과 조교수

관심분야: Ad-hoc Network, Sensor Network, Microgrid

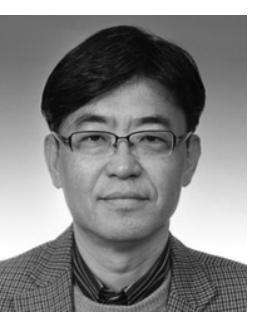

김 학 만

e-mail :hmkim@incheon.ac.kr

1998년 성균관대학교 전기공학과(박사)

2011년 일본 Tohoku(東北)대학교 정보과 학과(박사)

1996년 2008년 한국전기연구원 선임연구원 현 재 인천대학교 전기공학과 교수

관심분야: Smartgrid, Microgrid, 신재생에너지시스템, 전력변환 기반 전력시스템 